\title{
Paradox Lost: Time Travel and Free Will in the Television Show Lost
}

\section{Abstract}

The television series Lost uses the motif of time travel to consider the problem of human free will, following the tradition of Humean compatibilism in asserting that human beings possess free will in a deterministic universe. This paper reexamines Lost's final mystery, the "Flash Sideways" world, presenting a revisionist view of the show's conclusion that figures the Flash Sideways as an outcome of time travel. By considering the perspectives of observers who exist both within time and outside of it, the paper argues that the characters of Lost changed their destinies, even though the rules of time travel in Lost's narrative assert that history cannot be changed.

Keywords: Lost, time travel, Hume, free will, compatibilism

My purpose in this paper is twofold. First, I intend to argue that ABC's Lost follows a tradition of science fiction in using time travel to consider the problem of human free will, making an original contribution to the debate by invoking a narrative structure previously unseen in time travel stories. I hope to show that Lost, a television show that became increasingly invested in questions over free will and fate as the series progressed, makes a case for free will in the tradition of Humean compatibilism, asserting that human beings possess free will even in a deterministic world.

Secondly, in making my argument, I also hope to give the ending of Lost a long overdue redemption. After the series finale, critics and fans alike panned the show's ending, accusing it of relying too heavily on mysticism and failing to provide an adequate explanation for the many mysteries that populated the Island. This paper will make the case that Lost's ultimate revelation relied just as heavily on science fiction as it did on mysticism, allowing for a fitting end to a series 
that so often blurred the lines between science and faith. In the resolution to its final mystery, Lost settled on a view of time in which the universe has one fixed and unalterable timeline. Characters can travel through time, but they evidently cannot change history. Despite this insistence on time as unchangeable, I will argue that time travel allowed the characters of Lost to exercise free will and change their destinies.

I will begin by showing why a reexamination of Lost's ending is necessary, then I will present a reinterpretation of the show's final mystery, the "Flash Sideways" world depicted throughout season six. My revisionist view of the ending will figure the Flash Sideways as an outcome of the characters' time-traveling. I will review David Hume's celebrated compatibilist-determinist approach to the free will question, and I will then show how Hume's philosophy aligns with my interpretation of Lost's depiction of the rules and effects of time travel. To conclude, I will explore the consequences of my interpretation, showing how the series presents a worldview in which, even in a deterministic setting with intractable causes and effects where history cannot be changed, human beings are still free to choose their own fate.

\section{Returning to "The End"}

Those left unsatisfied by the ending of Lost generally fall into two camps. The first camp consists of those viewers for whom the final episode served as a microcosm for the whole series in its apparent refusal to answer the show's most pressing question: What is the island? To this first camp, I can offer no solace. The answer to this question, at least to the furthest extent that the show's writers were ever willing to answer it, had already been provided in a series of hints and indirect revelations long before the show's final episode. The Island, we come to understand, is part of a geographical formation that moves through time and space, existing in an ever-shifting spatial-temporal coordinate; entrance from and exit to the Island is complicated by the time difference between the Island and the surrounding geography. The Island is populated by longterm residents who have honed their understanding of the island's time-shifting into abilities that strike the uninitiated as mystical, even godlike. Even armed with such an answer, those in this first camp may justifiably ask, "Why?", to which neither the series nor I have any good response. 
The viewers in the second camp are aware that Lost had gone as far as it was willing to go in explaining the properties of the Island, and they have accepted that the show's final episode was tasked with answering a different question, namely providing the origin and nature of the Flash Sideways world introduced in season six. For these viewers, an answer was indeed provided, albeit one that seemed unpalatable. The Flash Sideways was revealed to be purgatory, or at least something very much like purgatory:

JACK. Where are we, Dad?

CHRISTIAN. This is the place that you...that you all made together, so that you could find one another. The most important part of your life was the time that you spent with these people. That's why all of you are here. Nobody does it alone, Jack. You needed all of them, and they needed you. JACK. For what?

CHRISTIAN. To remember... and to... let go. (“The End”)

By itself, this revelation - that the Flash Sideways is part of the afterlife - raises no concerns. It satisfactorily explains why the characters appeared to be living in two divergent realities in season six. It is problematic, however, when considered in the context of all that came before it. Eric Guttormson, writing for his blog on the website Eric Knows It All, articulates the underlying problem:

I think I know why some folks have had a very hollow feeling after the finale of Lost. ... It's because of the prevailing notion that the ALT (alternate timeline, or Flash Sideways) was merely purgatory, the same purgatory that any of us would eventually experience when we die. ... If the ALT or sideways reality was just your run-of-the-mill purgatory then...we don't need a mysterious island to get there. We don't need time travel, we don't need to be avoiding a smoke monster, and we don't need to explode a nuclear bomb in an attempt to "set things right." ... [I]f the purgatory ending wasn't directly caused by the "incident" then all of the story leading up to it was just window dressing.

As Guttormson observes, for an audience to accept a narrative, its ending needs to come across as motivated by the chain of events preceding it. Lost's ending seems to outright reject this 
expectation by treating the aforementioned "incident" as a red herring that appeared to set up, but was ultimately not responsible for, the Flash Sideways.

Season six of Lost is built on the tantalizing possibility that the characters managed to change their destinies by time traveling. The final few episodes of season five, starting with "The Variable" and continuing through "The Incident: Part 2," depict Jack and his friends trying to bring to fruition a plan envisioned by the physicist character Daniel Faraday. Faraday theorized that detonating a hydrogen bomb in 1977 would break the chain of events leading to the 2004 plane crash bringing Jack and company to the Island. Although Faraday had previously insisted that time cannot be changed, he revised his theory in "The Variable," having determined that an event with sufficient magnitude could indeed change the course of history.

Faraday dies before he can put his plan into practice, but Jack and the other survivors stuck in 1977 continue to carry it out. Season five ends with Juliet banging a rock on the shell of the nuclear bomb, followed by a burst of white light; season six begins in the Flash Sideways world, where we quickly learn that the Island is underwater and Oceanic Flight 815 does not crash. It would seem that the survivors were at least partially successful, for, although they are unaware of it, they seem to have created an alternate timeline. The show's conclusion, though, raises doubts about the characters' success in their attempt to change history. Because the Flash Sideways is revealed to be part of the afterlife, then it may have nothing at all to do with the detonation of the nuclear bomb. The survivors, despite the season's initial appearances, seem to have failed to change time. I intend to make the case, however, that they did, although not in the manner they intended, nor in a way seen previously in any other time travel story.

\section{The Flash Sideways as Lost Time}

I wish to preface my theory of the Flash Sideways by noting that it rests on the premise that Daniel Faraday is always right. Faraday's depiction as an absent-minded professor figures him firmly in the position of the "wise old man" character type. In The Archetypes and the Collective Unconscious, Carl Jung writes, "The old man knows what roads lead to the goal and points them out to the hero. He warns of dangers to come and supplies the means of meeting them effectively" 
(221). In order to fulfill his narrative function, the wise old man character needs to be fully versed in the rules of the hero's world. Faraday functions as a sort of gatekeeper of the rules of time travel, but his authority as rule-keeper is complicated by the fact that he introduces two different sets of contradictory rules.

When the characters stranded on the Island are first traveling randomly through time at the beginning of season five, Faraday insists that history cannot be changed and that time travelers cannot alter what they already know to be the future:

FARADAY. You cannot change anything. You can't. You can try to. Wouldn't work. SAYWER. Why not?

FARADAY. Time, it's like a stream. Now we can move forward on that stream, we can move in reverse, but we cannot, ever, create a new stream. If we try to do anything different, we will fail. Every time. Whatever happened, happened. (“Because You Left”)

In this, his initial view of time travel, Faraday's theory is reminiscent of theoretical physicist Igor Novikov's "self-consistency" principle. This principle allows for the possibility of time travel within existing physical laws so long as the act maintains one coherent view of spacetime and avoids paradoxes (Jaffe 620).

The characters' experiences throughout season five appear to bear Faraday's hypothesis out. In one of the more radical attempts to alter the timeline, Sayid shoots the twelve-year-old Ben Linus in 1977. This shocking event marks the end of an episode, instilling in viewers a sense of cognitive dissonance as they linger on the lifeless image of a child whom they know should still be living as an adult. The next episode, however, definitively reiterates the self-consistency principle, revealing that Ben's wound was not fatal and that his mysterious healing at the hands of the Others will leave him with no memory of the event. What had seemingly been identified by Hurley as an inconsistency in the timeline is explained away; the adult version of Ben's apparent failure to recall being shot by Sayid no longer constitutes a paradox. The show's writers even go as far as using an extra-narrative device to endorse the self-consistency principle, titling the episode, "Whatever Happened, Happened." That phrase becomes Lost's mantra for underscoring Faraday's first theory: the intractability of time. 
This dogmatic adherence to what the show repeatedly insists is its cardinal rule of time travel makes it that much more surprising when Faraday suddenly revises his thesis in the episode "The Variable." Faraday, who has spent his last three years working among Dharma Initiative scientists in Ann Arbor, returns to the Island with a radically altered theory about how time travelers can affect the course of history. He tells Jack he has been reviewing his life's work on time travel, and he discovered something that could make changing the past possible. "I'd been spending so much time focused on the constants," he says, "I forgot about the variables." He goes on to insist that these forgotten variables are people. According to Faraday, "We think, we reason, we make choices, we have free will," and once people accept that they can change the past and actually try to do so, they will succeed.

It seems out of character for a scientist such as Faraday to suddenly conclude that faith has been the missing ingredient in time travelers' efforts to alter history, and it seems even more unlikely that Faraday would have so long overlooked the capacity of human beings to function as parts of his equations. After all, we have known since season four that Faraday has long stressed the importance of human beings functioning as "constants" in the mathematics of time travel. Deleted lines forming an extended scene from "The Variable" clarify that Faraday thought it was more than a matter of faith. What had been lacking in previous attempts to change the past, he explains, was not only sufficient belief that it could be done, but also sufficient magnitude in the attempts.

Returning to the metaphor of time as a stream, he presents a key distinction between attempts that will fail and those that will succeed:

FARADAY. In laymen's terms, a creek keeps washing over any pebble thrown into it. Pebble represents a change - small change. Creek is time. ... If we accept that we can't change the past, can't do anything about it, then we don't even bother trying. But if we decide, if we believe that we can change the past, then we don't use pebbles, Jack. We use boulders. (drops a rock into the creek)

You see? 'Cause if you drop a big enough rock into a creek, you create a dam, right? And then that creek changes. 
Faraday's metaphor implies that small-scale actions will have no effect on the timeline, but an action on a large enough scale might be able to push the stream of time so far away from its original destination that a new stream is created. For Faraday, the event that could prove to be large enough to permanently alter time is the detonation of a hydrogen bomb.

Daniel Faraday presents two theories that appear to be at odds with one another:

1) Time cannot be changed, even by time travelers.

2) Time can be changed by time travelers, provided those travelers effect a sufficiently large action.

Are these two rules mutually exclusive, or is it possible to resolve them? I believe there is one interpretation of the events in Lost that would make Faraday right on both counts.

When we are first introduced to the Flash Sideways world in the season six premiere, we are led to believe that it is an alternate timeline created by the detonation of the nuclear bomb. By the end of the season, though, it has become clear that the actions taken by Jack and the other main characters actually ensured the existence of the very future they were trying to prevent, in what James Gleick would call a "predestination paradox" (231), long a staple of time travel stories. While some viewers assume the nuclear bomb did not actually explode, there is compelling evidence that the bomb did explode and that its blast was indeed what neutralized the rapidly leaking electromagnetic energy inadvertently released by the Dharma Initiative's drilling. In attempting to destroy the Island, Jack likely saved it. The timeline of Lost as we know it was preserved, and the incident at the Swan drilling site can be recognized as an integral part of the causal chain of events forming the reality that Jack, the survivors, and Lost's viewers know.

This does not mean that Jack did not change time. If we operate on the premises that Faraday's second rule is true - that a hydrogen bomb is of sufficient magnitude to create a new timeline - and that the bomb did go off, then Jack did change time. However, instead of changing it from the reality we already know, he changed it to the reality we already know.

If we think of the detonation as responsible for changing history to the timeline we already know, then both of Faraday's rules can be true, depending on one's perspective - whether one is observing the events from within time or from outside of time. From the point of view of an observer 
within time, the timeline was not changed. Past, present, and future have been and will always be immutable. Envisioned in this way, time can be thought of as unchangeable points all laid out in a sequence on a geometer's line (Gleick 257). A time traveler can move from one point on the line to any other point, but the line itself, including the continuum of points that comprise it, cannot change. From the point of view of an observer outside of time - call it the God viewpoint, perhaps, or the view of the author - the line did change. Here, "change" is a relative term, since a "change" normally implies an act with both a before and after; in other words, change is normally considered in terms of time. An atemporal God, however, would not experience events in succession (De Florio and Frigerio 8). There would be no before and after, only a timeless from and to.

Time changed to reality as the characters know it, but what did it change from? The Flash Sideways serves as the answer. Existing outside of time, the Flash Sideways is reality as it would have been - one could even argue as it should have been. It is "lost time," a timeline prevented from existing when the characters successfully detonated the nuclear bomb. Put another way, the Flash Sideways is destiny.

\section{A Case Study in Compatibilism}

Lost contains countless allusions to philosophy, most noticeably in the names of some its characters: Edmund Burke, Jeremy Bentham, Mikhail Bakunin, and, most germane to this essay, Desmond David Hume. In a bit of heavy-handed symbolism, Desmond's name and nationality link him with the Scottish philosopher David Hume, originator of the compatibilist view of free will.

David Hume was a champion of free will partially because, like so many of the rest of us, he simply wanted it to be true. In Hume's eyes, a God who engendered a world with free will inspires greater awe than a God who created a world he fully controlled:

It argues surely more power in the Deity to delegate a certain degree of power to inferior creatures, than to produce every thing by his own immediate volition. It argues more wisdom to contrive at first the fabric of the world with such perfect foresight, that, of itself, and by its proper operation, it may serve all the purposes of Providence, than if the great Creator were obliged every moment to adjust its parts, and animate by his breath all the wheels of that stupendous machine. (Hume 82-

83) 
To make his case for the delegation of "a certain degree of power to inferior creatures," Hume needed to show how such power was possible in a deterministic world. He insisted that all philosophers, regardless of whether they believed in free will, acknowledged that nature and human thought operated wholly on immutable processes of cause and effect (Hume 102). He saw this belief in a necessary chain of events as the common ground where all philosophers engaged in the free will question needed to begin. For Hume, the best human beings could hope for was free will that was somehow compatible with a divinely determined world. This is precisely what Hume, and his generations of disciples, argue for. Compatibilists in the Humean tradition believe that, even though the universe is deterministic, humans have the capacity to do other than what they ultimately do (Beebee and Mele 202). Even though they will not do other than what they have been divinely and naturally determined to do, they could.

From the perspective of Humean compatibilism, although we know which road will be taken, there is always a road not taken - one that could have been, but was not, taken. If free will is present, then alternative possibilities must exist. One cannot experience these possibilities, of course, because they are never actualized. They do not exist within time. Even a time traveler moving forwards and backwards in time could not encounter these possibilities. If such a possibility were to exist in any tangible way, it could only do so in a metaphysical or spiritual realm that was entirely removed from time, as is the case with the Flash Sideways.

Lost goes out of its way to stress the timeless nature of the Flash Sideways. In the closing moments of the series, in the final scene in the Flash Sideways, Jack finds himself face to face with his father Christian. In both the primary timeline and the Flash Sideways, Jack has been chasing his dead father literally and figuratively. Finally, it seems, Jack and the viewers will get some answers, for Christian is in a unique position to comment on the mysteries of Lost. Referring to Christian, Melissa Ames remarks, "When [a father] is portrayed as bodiless, as a deceased father would be, he can represent more than he was; he can stand for the Law, for the Idea of authority, for the Symbolic realm as a whole" (434). Christian, who was portrayed as "bodiless" in that his body was missing in both the primary timeline and the Flash Sideways, emerges as a symbol for both the world of the living and the world of destiny. Removed from both, he can comment on how the two realms function cooperatively. Although we do not get much, Christian 
gives us two crucial pieces of information needed to make sense of the relationship between the Flash Sideways and the "real world". First, Christian explains that neither the Flash Sideways nor Jack's lifetime should be thought of as anything other than reality: "I'm real. You're real. Everything that's ever happened to you is real." Soon afterwards, Christian says something odd about the nature of time in the place where he and Jack are speaking: "There is no 'now' here" ("The End"). Indeed, the Flash Sideways appears to lack a definitive "now." The passage of time is not consistent for characters; what some characters experience in a week, other characters experience in a day or two. For example, Jin and Sun only experience one night between the landing of Oceanic Flight 815 and the death of Keamy. Sayid, on the other hand, experiences at least two nights between these same events. A distorted sense of time can also be witnessed in the events leading up to the piano concert. In the period between the wait staff laying out the tables for the concert and the concert's beginning, some characters experience an entire week.

These details underscoring the "timelessness" of the Flash Sideways world invite viewers to consider the world as something similar to, but ultimately different than, an alternate timeline. Characters experience sequences of causally related events, and the characters are allowed to interact with each other and share common moments; however, time as a unifying and consistent force has been stripped away. In this respect, the Flash Sideways resembles a mental construct such as a dream or an act of imagination - the same sort of imagination that allows human beings to consider sets of alternate possibilities before choosing an action. This power has long been considered a vital component of free will. In "Free Will and the Construction of Options," Chandra Sripada asserts that agents who make free decisions are psychologically enabled by two different types of capacities: constructive processes and selective processes. Constructive processes allow for the agent to mentally create a set of candidate outcomes; selective processes enable the agent to compare the available outcomes and assign evaluative weights to each option. The candidate receiving the most weight is then selected as the action (Sripada 2915). In making a rational choice, the human agent has used constructive processes to transition from infinite possibilities into a finite number of options, and evaluative processes to ultimately enact one actuality. Human beings make an immeasurable number of these choices daily. Because life is determined through this constant, complex network of choices forming actualizations from infinite possibilities, 
the role choice plays in determining our reality must be relieved of its complexity to function as a theme in fiction. To do so, contemporary fiction tends toward symbolism, highlighting choice by depicting "frozen moments" in which one instant, one gesture becomes the stylized sign for a state which is so pervasive that it can never be captured as it truly exists (Wright 278). Lost employs the nuclear bomb as such a symbolic device. In fact, to allow us to consider the ramifications of the characters' choice to detonate the bomb, we are presented with two worlds: one where the bomb exploded, and one where it did not. Lost is not the first story to present two different worlds showing the results of two different approaches to a key character choice. What makes Lost unique, rather, is the way it thwarts its viewers' expectations. We expect that the "new" world we are seeing in season six, the Flash Sideways world, is the one exemplifying what happens/would have happened when Jack detonates the bomb. Instead, as it ultimately turns out, the Flash Sideways world is the one showing what happens/would have happened when Jack did not choose to detonate Jughead. Lost is able to achieve this sly bit of narrative misdirection by exploiting our preconceived expectations about time travel stories.

Considering a well-known, lighthearted example of time travel storytelling, Back to the Future, may help to illuminate these preconceptions. The original Back to the Future film proceeds as a time travel story typically does. A central character, teenaged Marty McFly, begins in a version of the present - 1985 in this case - uncorrupted by the interference of time travel. His parents are social misfits, his mother suffering from chronic depression and alcoholism and his father too timid to stand up against a bullying coworker. Marty, using a time-traveling car, travels back to 1955 , inadvertently preventing a key event in his parents' courtship. As the story goes, Marty takes drastic steps to get his mother to fall in love with his father as history intended, ensuring that his parents will get married and that he will continue to exist. Although he succeeds, the mechanisms that allow him to do so result in his father's triumph in 1955 over the same bully who would have continued to torment him, had Marty not interfered with history through his time traveling. Marty returns to 1985 to find that his accidental altering of time has led to a revised 1985 in which his mother and father are happy and deeply in love and the bully no longer exerts any power over his father. All is as it should be - better than it should be, as it turns out. 
Back to the Future is presented as a time travel story normally unfolds, beginning with an uncorrupted present, progressing to the past, then returning to an altered present. Lost, however, thwarts its viewers' narrative expectations by beginning the story in the altered present. Imagine a version of Back to the Future beginning in the altered 1985, told from the perspective of successful science fiction author George McFly, Marty's father as he appears in the revised 1985 at the end of the movie. For this George McFly, the circumstances in which he is a happily married author whose erstwhile high school bully has been reduced to waxing his car are simply reality. What this George McFly fails to understand is that his good fortune is a result of cheating destiny, thanks to his time traveling son. What he also fails to understand is that somewhere out there in spacetime there is another George McFly, with oily hair and horn-rimmed glasses - the George McFly he was supposed to be. Which George McFly is real? Did the oily-haired, nerdy version of George McFly fade away from existence? Did he never really exist to begin with, since a comprehensive, finished view of Back to the Future's ultimate timeline doesn't incorporate the oily-haired George McFly? In other words, if a person, or perhaps a certain version of a person, was supposed to exist but did not exist because the free will of human beings changed the course of events, what happens to that version of that person?

We can think of Lost's Flash Sideways as an answer to that very question.

\section{A Destiny Rejected}

The word destiny normally implies a positive connotation. When we say that two people were destined to meet, or that something was destined to happen, we say so with the expectation that the meeting or event will lead to some hoped-for outcome. The two people "destined" to meet may go on to form a lasting relationship, or the event may lead to some good fortune down the road, perhaps in a way difficult to predict. As a word, destiny is loosely synonymous with fate, the key difference being that fate's connotation is more ambiguous. While we may say that good things were "fated" to occur, we also use "fate" to describe something human beings struggle against. Consider the terminology we adopt in the free will debate: We often use "fate" to stand for determinism. We frequently use the phrase "free will versus fate," yet we are unlikely to say "free 
will versus destiny." Perhaps this is because destiny so often refers to an idealized version of events. Why would anyone ever want to have free will, if the price was the loss of our destiny?

As Lost moves toward its conclusion, this question becomes ever more present. Joanne Morreale observes, "[t]aking control of one's destiny becomes the motivating quest, as, up until the end, the characters struggle with the possibility (or impossibility) of changing fate" (183). In the traditional interpretation of the show's ending, changing fate was exposed as an impossibility. In my interpretation, the characters did change fate, even though they could not rewrite time. By detonating Jughead, the characters successfully wrestled from fate a degree of control over their lives, however disappointed they may have been to discover that doing so resulted in no change from the reality they already knew. What they did not know, though, and, with the notable exception of Desmond, would not know until after their deaths, was that they had nullified a world provided for them by destiny.

This world, the Flash Sideways world, presents us with a curious test case, one allowing us to consider whether these characters would have been better off if they had left their lives to the unaltered course of destiny. As Morreale notes, characters in the Flash Sideways world "become mirror images of themselves, for the most part living the lives they wish they had had" (181). Jack is a father forging the kind of relationship with his son he never achieved with his own father; Hurley's lottery winnings have fashioned him into a successful philanthropist and businessman, allowing him to call himself lucky rather than cursed; Jin and Sun have a relationship unblemished by mistrust or infidelity; Desmond has the respect of Charles Widmore, who now employs him rather than torments him. Even the characters experiencing some kind of misfortune, like Kate and Sayid, appear to be facing the consequences of cosmic justice, as if they were experiencing the kind of punishment that was always fitting for them. Indeed, this is their world as it was supposed to be, a world free not only from the interference of time travel, but also from the symbolic interference of the Island.

At first glance, it appears that Jack and his friends made a terrible mistake. By rejecting destiny, they seem to have foregone much that they desired. Jughead's detonation not only preserved the timeline as they already knew it, but it also wiped away the possibility of a providential paradise where they lived, for the most part, rich and fulfilling lives. This would seem to be a curious lesson 
for Lost to offer: Meddle not in the affairs of fate, mortals, or ye shall make things worse than they otherwise would have been. More likely, we are meant to take a different idea away from this unfulfilled destiny. Whether we have control of our lives in the form of free will, or whether all our choices are determined, our lives will always constitute but one reality amidst an infinite sea of alternatives. There will always be unrealized possibilities. For the viewers of Lost, as well as for its characters, one of the greatest challenges of life is letting go of these unfulfilled destinies.

Lost is a show about salvation. All of its characters need to be saved, in a variety of literal and figurative ways (Ames 443-44). Even when the characters are saved, however, closure still proves elusive. This can be seen in the characters who are literally saved from the Island, who only end up compelled to return. It can also be seen in the characters who seek psychological salvation; often, redemption proves more difficult than they expected. Both Locke and Sawyer expect to find closure in killing Anthony Cooper, but neither one of them gains any satisfaction from the act of revenge. Ben has spent over a decade waiting to see Jacob in the flesh, but, when the long hopedfor meeting finally occurs, Ben is told he is not as important as he always thought he was. Sayid, upon learning that he has finally killed everyone responsible for Nadia's death, finds himself without a purpose. On Lost, the constant cycling of character objectives parallels the unravelling of the show's mysteries: Just as the answer to one question always comes with a new series of questions, the achievement of one character's objective always comes with a whole new slate of obstacles.

Two characters become cognizant of this cycle and attempt to break it. The peace they find in doing so stands as a testament to the power of letting go. Even though they have been caught up in the unpredictable time shifts, Rose and Bernard choose to accept the life they have been given instead of trying to rectify it. When Sawyer, Kate, and Juliet find them and learn they have been living by themselves for three years, they are surprised, but Rose and Bernard explain the value in what they have been doing:

SAWYER. So y'all been scavenging food and living out in a hut by yourselves?

ROSE. People try their whole lives to get themselves a nice, quiet place near the ocean where they can live in peace. And we did it. That's what we made for ourselves. 
SAWYER. Well, I hate to rain on your parade, but your condo's about to go ka-blooey.

KATE. Jack has a bomb.

ROSE. Who cares?

KATE. Excuse me?

ROSE. It's always something with you people. Now you say Jack's got a bomb. And what, you guys are all gonna try to stop him, right?

JULIET. Yeah, that's right.

ROSE. We traveled back thirty years in time, and you're all still trying to find ways to shoot each other?

JULIET. Rose, we just need to know which way the DHARMA Barracks are from here so we can stop Jack, or you're gonna be dead. We all will.

BERNARD. So we die. We just care about being together. That's all that matters in the end. ("The Incident, Part 1")

As is so often true on Lost, a character's words are laced with dramatic irony. In this case, the full impact of Bernard's dialogue only becomes meaningful when we re-examine the moment in the context of the show's ending. Being together, as it happens, is so important for the characters of Lost that it allows them to finally accept the reality they lived, and to let go of the unrealized destiny represented by the Flash Sideways.

\section{Choosing to Let Go}

Let us assume for a moment that Jack, Kate, Sawyer, and all of Lost's other characters were cogs in a deterministic machine. Let us imagine that the experiences and genetics that formed them psychologically and physiologically compelled them to act as they did, making one predetermined set of choices, each choice leading to predictable outcomes. From the moment they were born until the day they died - which for Jack was on the Island at the end of the series and for Kate and Sawyer was much later, presumably years after the time depicted in Lost's final episode - they were subject to the authority of an unbreakable timeline. Even if we operate under this assumption, we cannot claim that the characters never exert any free will, because the characters are also 
depicted outside of the time between birth and death. In this reality, the Flash Sideways world, the characters make a collective choice that arises from their free will, a choice undictated by any timeline.

As mentioned above, the characters' experiences in the Flash Sideways, although occurring out of time, are not unreal. "Everything that's ever happened to you is real," Christian tells Jack, and many things have happened to Jack in the Flash Sideways. In her article "Music of Other Spheres: Diagonal Time and Metaphysics in Lost," Isabella van Elferen examines how the musical effects used to underscore transitions between present moments and flashbacks, flash-forwards, and flash-sideways signify that Lost has no definite realities to shift between (258). "[L]inear time and timelessness, Being and Nothing, occur in this series with similar weight and frequency," van Elferen contends (261). Because the linear time of the characters' lives and the timelessness of the characters' experiences in the Flash Sideways are given equal weight, all of the characters in the Flash Sideways who "remember" their lives are confronted with two realities, side-by-side. Leaving the Flash Sideways is more than rejecting an illusion; instead, it is a conscious choice to let go of one reality and to accept another - even if that means letting go of something ongoing in favor of a life that is already complete and unchangeable. That this choice is an act of free will for Jack and the other characters in the church is emphasized by the characters who deliberately choose not to move on, namely Ben and Eloise Hawking.

Lost's ending is a strange marriage of philosophies. In deciding to accept their lives as they lived them, the characters employ free will to choose determinism, yet they also choose a reality that they themselves had a hand in creating. In a powerful act of symbolism, they opt for the imperfect lives they created in time in favor of the idealized lives destiny had in store for them. Perhaps they are not leaving destiny entirely behind, though. It seems unlikely that a show like Lost would depict characters moving on to one world while leaving another completely behind. Throughout its run, Lost frequently complicated the idea of binaries - not only exploring resolutions between free will and fate, but also such dichotomies as good and evil, life and death, and science and faith. Noting that other science fiction works tend to deconstruct and reject dualities inherent to the human condition, Kryn Freehling-Burton observes, "Perhaps these dualities do not completely disappear on Lost but they are challenged and in some cases the dualities are multiplied into a continuum of 
possibilities" (81). Remarkably, this proves to be true even for one of Lost's most famous catchphrases, "Live together, die alone." Not only do characters occasionally die together, but they come together afterwards, still working collectively to make choices and continue the story.

\section{Works Cited}

Ames, Melissa. "Where Have All the Good Men Gone? A Psychoanalytic Reading of the Absent Fathers and Damaged Dads on ABC's Lost." Journal of Popular Culture, vol. 47, no. 3, 2014, pp. 430-50. Wiley Online Library, doi:10.1111/jpcu.12139.

Back to the Future. Directed by Robert Zemeckis, Universal Pictures, 1985.

"Because You Left." Lost, season 5, episode 1, written by Lindelof, Damon, and Carlton Cuse, ABC, 21 January 2009.

Beebee, Helen, and Alfred Mele. "Humean Compatibilism." Mind, vol. 111, no. 442, Apr. 2002, pp. 201-23. Humanities International Complete, doi:10.1093/mind/111.442.201.

De Florio, Ciro, and Aldo Frigerio. "In Defense of the Timeless Solution to the Problem of Human Free Will and Divine Foreknowledge." International Journal for Philosophy of Religion, vol. 78, no. 1, 2015, pp. 5-28. Academic Search Premier, doi:10.1007/s11153-014-9471-4.

Freehling-Burton, Kryn. "Lost Mothers: The 'Othering' of Mothers on the TV Show Lost." Femspec, vol. 12, no. 2, 2012, pp. 66-84. Humanities International Complete, https://login.ezproxy.lib.uwstout.edu/login?url=http ://search.ebscohost.com/login.aspx?direct=true\&db=hlh\&AN=83698299\&site=ehostlive\&scope=site. Accessed 13 Aug. 2018.

Gleick, James. Time Travel: A History. Vintage Books, 2016.

Guttormson, Eric. "Understanding the Finale of Lost (Sideways Reality Theory)." Eric Knows It All, WordPress, 27 May 2010, ericknowsitall.com/lost-finale-review-explanation/. Accessed 13 Aug. 2018.

Hume, David. An Inquiry Concerning Human Understanding. Edited by Charles W. Hendel, BobbsMerrill, 1955. 
Jaffe, Andrew. "Physics: The Time Lord and Fellow Travelers." Nature, vol. 502, no. 7473, 31 Oct. 2013, pp. 620-22. Academic Search Premier, doi:10.1038/502620a.

Jung, Carl. The Archetypes and the Collective Unconscious. Translated by R.F.C. Hull, 2nd ed., Princeton UP, 1968.

Morreale, Joanne. "Lost, The Prisoner, and the End of the Story." Journal of Popular Film and Television, vol. 38, no. 4, 2010, pp. 176-85. Academic Search Premier, doi:10.1080/01956051.2010.508504.

Sripada, Chandra. "Free Will and the Construction of Options." Philosophical Studies, vol. 173, no. 11, 2016, pp. 2913-933. Springer Link, doi:10.1007/s11098-016-0643-1.

“The End." Lost, season 6, episode 17, written by Lindelof, Damon, and Carlton Cuse, ABC, 23 May 2010.

“The Incident." Lost, season 5, episodes 16 and 17, written by Lindelof, Damon, and Carlton Cuse, ABC, 13 May 2009.

van Elferen, Isabella. "Music of Other Spheres: Diagonal Time and Metaphysics in Lost." Science Fiction Film and Television, vol. 3, no. 2, 2010, pp. 253-70. ProQuest International Index to Performing Arts, https://login.ezproxy.lib.uwstout.edu/login?url=https://search-proquestcom.ezproxy.lib.uwstout.edu/docview/821045086?accountid=9255. Accessed 13 Aug. 2018. "Whatever Happened, Happened." Lost, season 5, episode 11, written by Cuse, Carlton, and Damon Lindelof, ABC, 1 Apr. 2009.

Wright, Terence. "Choice and Choosing in Fiction." Modern Language Review, vol. 83, no. 2, 1988, pp. 273-86. Academic Search Premier, doi:10.2307/3731679. 